\title{
Bernese Mountain Dog
}

National Cancer Institute

\section{Source}

National Cancer Institute. Bernese Mountain Dog. NCI Thesaurus. Code C53761.

The Bernese Mountain Dog is a sturdy, heavy dog, with a weather-resistant, tri-color double coat. The dog has a white blaze on the chest, white on the head and toes, and rust markings over each eye, on the cheeks, sides of the chest, under the tail and on each leg. The broad head has a slight furrow down the middle. The medium-sized triangular ears are pendant. Height: $23-28$ inches (58-71 cm.) Weight: 80-110 pounds (36-50 kg.) 